\title{
Selection of Shaft Sinking Method for Underground Mining in Khalashpir Coal Field, Khalashpir, Rangpur, Bangladesh
}

\author{
Atikul Haque Farazi ${ }^{1}$, Chowdhury Quamruzzaman ${ }^{2}$, Nasim Ferdous ${ }^{3}$, Md. \\ Abdul Mumin ${ }^{4}$, Fansab Mustahid ${ }^{5}$, A.K.M Fayazul Kabir ${ }^{6}$ \\ 1,2,3,4, 5, 6 (Department of Geology, University of Dhaka, Bangladesh)
}

\begin{abstract}
Khalashpir coal field is the $3^{\text {rd }}$ largest coal field in Bangladesh, where coal occurs at depths of $257 \mathrm{~m}$ to $483 \mathrm{~m}$ below the surface. Considering the Geological, Geo-environment and other related geoengineering information, underground mining have been selected there to extract the deposit. In this paper, our concern is about shaft sinking method for underground mining. Depths of the coal seams reveal the necessity of a vertical shaft underground which again needs deep excavation. The problem arises with the excavation because of nearly $138 \mathrm{~m}$ thick Dupitila Sandstone Formation just $6 \mathrm{~m}$ below the surface in the area. It is loose, water bearing, containing dominantly porous and permeable sandstone and experiences massive water flow. So, the major concern is that any excavation through this will readily collapse and suffer massive water inrush. This will totally disturb the whole mining work progression and cause economic loss as well. By analyzing the ground condition of the Khalashpir cola field, artificial ground freezing has been identified most appropriate as shaft sinking method to control the ground water and to stabilize the loose soil during excavation. Lawfulness of the method and reason of neglecting other two common shaft sinking methods has been pointed out in this paper.
\end{abstract}

Keywords: Shaft sinking, freezing method, Ice wall, Ground Water, Caisson Sinking and Dewatering Method

\section{INTRODUCTION}

Korea South-South Cooperation Company (NAMNAM) in 2005 recommended on shaft location for the coal field. On the basis of the conditions in geological structure, hydro-geology, engineering geology and economical conditions they proposed the margin of Northwest of coal basin as shaft location [Map: 1]. Two boreholes GTB-1 and GTB-2 situated in the area was reported to be chosen to be two locations for two shafts. In this research, we have used borehole data of GTB-1 to get the stratigraphy.[Korea South-South Cooperation Corporation (NAMNAM) (2005) Recommendation on Selection of Conceptional Shaft Location on Khalashpir Coal Field (unpublished).](GTB-1 yields the following rock units from bottom to top of the ground:

- Gondwana Group

- Jamalganj Formation (Surma Group equivalent)

- Dupitila Formation

- Barind Clay Formation

Hydrgeological conditions of these units have been collected from pumping test results conducted in the borehole. By analyzing these information, we have discussed the feasibility of the freezing method over another two very common methods to serve the purpose of the shaft sinking in the Khalashpir coal field.

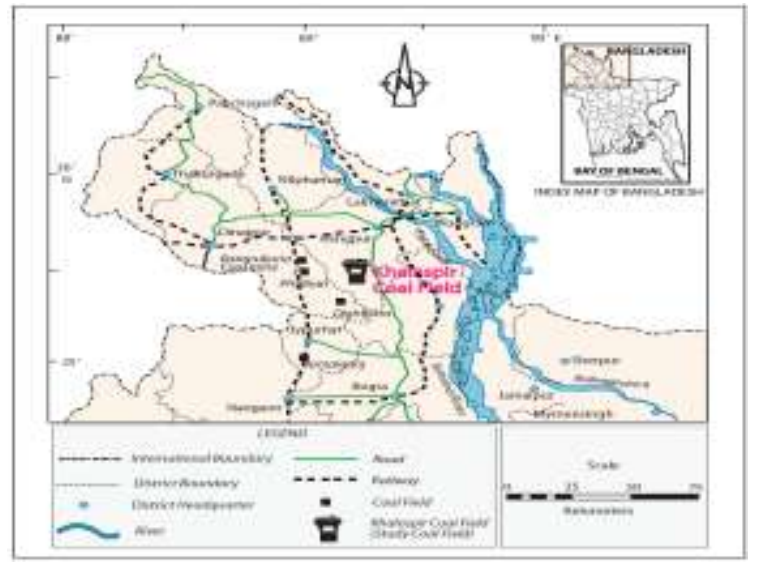

Map 1: Showing the location of the study area. 


\section{FREEZING METHOD}

Ground freezing has been serving for more than 150 years to support underground construction through unstable and water bearing ground as reliable one. Although patented by German scientist Potesch in 1883, it was first practiced in South Wales in 1862 to form a mine shaft. Overcoming the early stages, areas such as professional research, equipments, technology, and academy, construction level have witnessed rapid development. Its essential function is the solidifying, by freezing, of water bearing ground in which the shaft is sunk. It is also sometimes conducted into water bearing rock. Apart from protecting excavations ground freezing serves the purpose of stabilizing slips, sampling weak ground, constructing temporary access roads and maintaining permafrost below overhead pipeline foundations and below heated buildings.

The method is not limited by soil types and can form nearly all shapes frozen wall at any depth under any complex geologic and hydrogeologic conditions. It has been used for excavations up to $45 \mathrm{~m}$ diameter and to depths over $900 \mathrm{~m}$.

This method is totally environment friendly, safe, has minimum or nearly no effect on the groundwater level and water quality of the aquifer.

It is also mentionable that freezing method has been used successfully in Madhyapara Hard Rock Mining Project and Barapukuria Coal Mining Project of Bangladesh for mine shaft sinking where more or less same geological conditions prevail as Khalashpir coal field.

The preliminary objective is to remove hit from the ground below freezing point to form a vertical ice wall around the perimeter of the shaft prior to excavation. For this, freezing boreholes are drilled around the perimeter of the shaft and freezing pipes are installed within the boreholes. Depending upon the size and shape of the excavation freezing boreholes are configured.

The AGF is carried out in four stages, each of which is subjected to detailed monitoring:

1. Refrigeration plant and coolant distribution system installation

2. Construct ice wall by refrigeration

3. Maintenance refrigeration to allow excavation and installation of the permanent lining

4. Thawing of the frozen ground

Brine $\left(\mathrm{CaCl}_{2}, \mathrm{NaCl}\right.$ etc) solution is used as coolant for the refrigeration system. By circulating brine solution through the freeze tubes the ground is chilled to achieve ice wall. To achieve an average frozen ground temperature of $-10^{\circ} \mathrm{C}$ the brine needs to circulate at a temperature of around $-25^{\circ} \mathrm{C}$.

Combination of a compressor, condenser, evaporator and pumps with an ammonia-charged compression system is needed for a refrigeration system (Osborne J, Shaft Excavation In Frozen Ground At Point 5).

\section{LOGISTICS FOR RECOMMENDING THE FREEZING METHOD}

Stratigraphy, hydrogeology and geo-mechanical properties of the ground are responsible for the difficulties those the mine works would face due to deep excavation at that ground. So, to understand why the freezing method would be appropriate to choose for mine shaft sinking, we should know the stratigraphy, hydrogeology and geomechanical and geotechnical properties of soil there, and understand the extent of problems those can arise as response to excavation.

\section{STRATIGRAPHY}

As mentioned earlier, stratigraphy of the basin can be divided into four major units from bottom to top:

1. Gondwana Group

2. Jamalganj Formation

3. Dupitila Formation

4. Barind Caly Formation

Gondwana Group: The unit consists mainly of hard compact medium to coarse grained, often pebbly sandstones interbedded with some conglomerate, carbonaceous shale and coal. The base of the Gondwana group was not reach in any of the wells drilled and, therefore the total thickness of the unit is not known. However, a maximum thickness of $814 \mathrm{~m}$ of the unit was drilled in one of the wells. The age of the unit is Permian.

Jamalganj Formation (Surma Group equivalent): Above the Gondwana group lies a sequence of alternating sandstone and shale referred to as Surma group. The unit has a thickness about $184 \mathrm{~m}$; it is Miocene in age and overlies the Gondwana unit with an unconformity. It is found distinct that the shale layer is thick and its continuity is good (Thickness shale in GDH-45 11.0m). There are 8 shale layers with the thickness of maximum $9.6 \mathrm{~m}$ and minimum $1.2 \mathrm{~m}$ in GTB-1 and these layers exist with sandstone. These shale layers lie just above the coal seam and plays effective role as an impervious layer to water.

Dupitila Formation: This is a sand dominating unit and overlies the Surma group. It is composed mainly of loosely consolidated, medium to coarse grained, moderately sorted sandstone with few clay or shale interbeds and conglomerate sandstones and its continuity is not so good. Thickness of the units is $125 \mathrm{~m}$ on average. In GTB-1 138.5m thickness of the formation is found. It is Pliocene in age. Such kinds of rocks, as 
Selection Of Shaft Sinking Method For Underground Mining In Khalashpir Coal Field, Khalashpir, sedimentations with big voids are characterized by the fact that they have much underground water. Because of this loose, porous and water bearing nature, the Dupitila Formation would render coal mining, whether underground or open pit type, difficult. This is similar to Barapukuria coal field, Dinajpur district, Bangladesh where special freezing technique had to adopt in order to construct vertical shaft from the surface for underground mining.

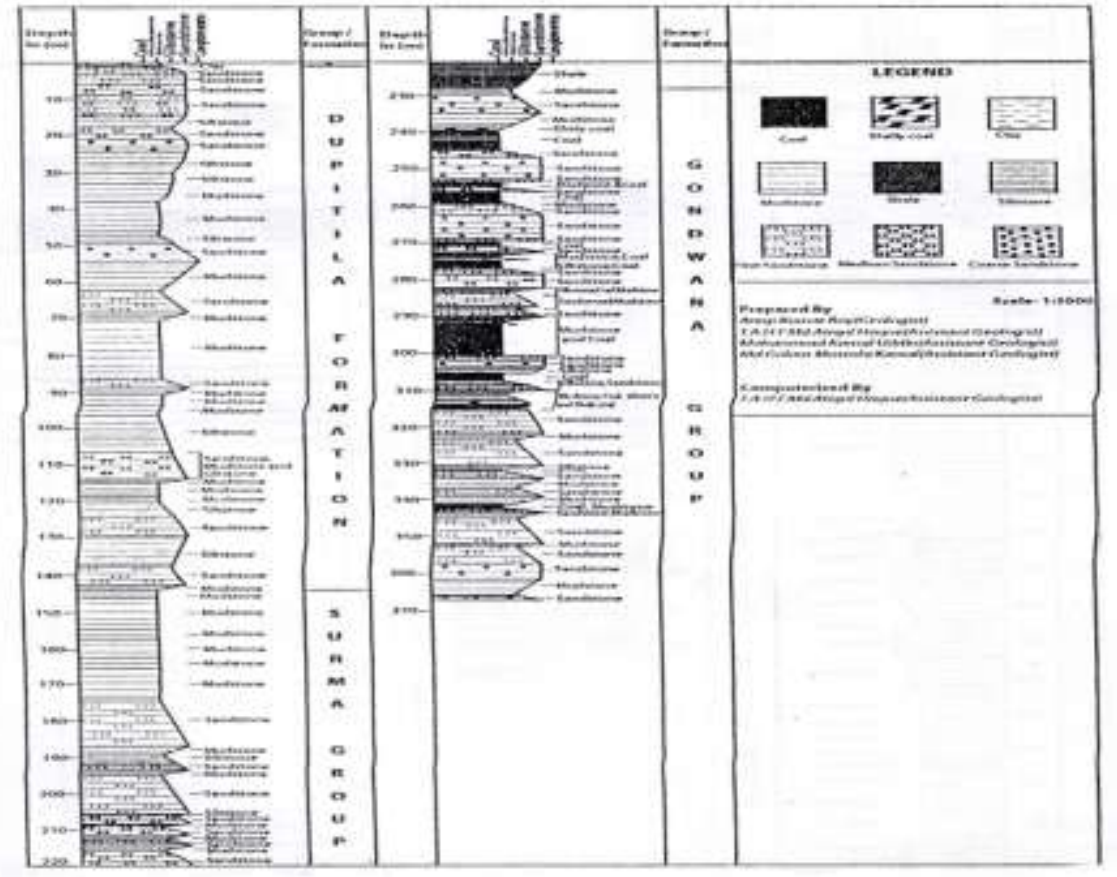

Figure: 2 Abridged stratigraphy of Khalashpir coal basin from borehole GTB-1(source: China Jinan Mining Development Corporation (2006) Techno-economic Feasibility Study of Khalashpir Coal Mine Project, Dhaka, Bangladesh.)

Barind Clay Formation: This is basically a clay unit, often silty has thickness of about $6 \mathrm{~m}$ and is covered by a thin veneer of alluvial at the top. The formation is Pleistocene in age. [Mondal Debasis, MSc thesis (2004) Selection of Mining Method in The Khalashpir Coal Field, Rangpur, Bangladesh] [(Dr. Yong Om Kil, Khalashpir Coal Mine Project, Pirjang, Rangpur (2005) Pumping Test Report of Exploration Boreholes on Khalashpir Coal Field (unpublished)] [figure: 2 ]

An abridged stratigraphy of the coal basin established from the borehole GTB-1 has been given in

\section{HYDROGEOLOGY}

The sedimentary basin of Khalashpir exhibits two main aquifers i.e., one is the aquifer of Dupitila group belonging to the Tertiary Period which contains sand, fine gravel, sandstone and conglomerate sandstone. And the other one is the aquifer of the Permian Period of the Palaeozoic Era which contains of conglomerate and sandstone lying below the Gondwana coal seams.

As mentioned above, these two aquifers were found in different geological eras and both them are all similar aquifers that belong to the category of groundwater.

\subsection{Aquifer of Groundwater of Dupitila Group}

This is the non-pressure water aquifer where water exists between the voids of sand and rocks in shape of gravitational water. This aquifer is $125 \mathrm{~m}$ thick on average.

The source of underground water supply is rainfall.

The flowing gradient of aquifer is $1: 1000$

The underground water of sedimentary basin gently flows in from the Northwest and out to the Southeast of the basin.

As for the water level of groundwater aquifer, the highest water level (surface level) appears in August and at the beginning of September, whereas the lowest water level $(-6 \mathrm{~m})$ becomes visible in April and the beginning of May. 
Selection Of Shaft Sinking Method For Underground Mining In Khalashpir Coal Field, Khalashpir,

Therefore, water level is $6 \mathrm{~m}$ differs during the periods of dry season and rainy season. The filtration coefficient of this aquifer is $346 \mathrm{~m}$ per day (GTB-1)

\subsection{Aquifer of groundwater of Gondwana Group}

This is the non-pressure water aquifer where the water exists between the voids of conglomerate sandstone particles.

Drilling of all the exploration boreholes deployed on Khalashpir coalfield was done up to and stopped at the layer of conglomerate laid below the coal seams and therefore the hydro-geological characteristics of the aquifer below the coal seams is not possible to be considered.

But it is thought that it will not be so detrimental to the coal mine development because this aquifer is located at the bottom of the coal seams.

Therefore, pumping test was made over the layer where medium to fine sandstone and coaly shale at the top of the basal conglomerate exist with coal seam.

The filtration coefficient of this layer is $0.065 \mathrm{~m}$ per day.

Surma group belonging to Miocene of the Tertiary period of the Cenozoic era is not a typical aquifer. But the pumping test was carried out because medium to fine sandstone and conglomerate sandstone are also lying in this layer with mudstone.

Filtration coefficient of this layer is $0.02 \mathrm{~m}$ per day. [(Dr. Yong Om Kil, Khalashpir Coal Mine Project, Pirjang, Rangpur (2005) Pumping Test Report of Exploration Boreholes on Khalashpir Coal Field (unpublished)]

Pumping test results from GTB-1, conducted both by Hosaf International Limited and China Jinan Mining Corporation is summarized below:

\begin{tabular}{|c|c|c|}
\hline Unit & $\begin{array}{l}\text { Unit inflow rate (average) } \\
\qquad \mathrm{M}^{3 /} \text { day } / \mathrm{M}\end{array}$ & $\begin{array}{l}\text { Filtration coefficient (average) } \\
\text { m/day }\end{array}$ \\
\hline Gondwana Group & 3.8 & 0.06 \\
\hline Jamalgang Formation & 0.89 & 0.02 \\
\hline Dupitila Formation & 661.33 & 34.67 \\
\hline
\end{tabular}

\section{Mechanical Properties}

The mechanical property that is considered primarily and importantly while dealing with a deep hole in the ground is its compressive strength. Soil with low compressive strength will suffer to sustain against pressure and vice versa in case of high compressive strength. Rock contents of Dupitila Formation are loose and low in compressive strength. Jamalganj Formation has moderately compacted rocks while rocks of Gondwana Group is very hard and highly compacted with high compressive strength. [Korea South-South Cooperation Corporation (1997) Construction of Skip Shaft-1 (Freezing Sinking Section) Technical Design]

\section{DIFFICULTIES}

Above information yielding loose, porous and permeable, low strength sand of Dupitila Formation which again suffers massive water inflow because of high conductivity. These will lead to following soilstructure interaction problems to any excavation at that ground:

- Massive water inrush into the hole

- Collapse of the structure due to lose nature of soil

The geological setting of the coal basin in Khalashpir is characterized by loose unconsolidated strata from surface to about $138 \mathrm{~m}$ below the ground level. In some places it extends further below. Under these conditions it is impossible to sink a shaft through conventional method of drilling and blasting.

\section{HOW THE FREEZING METHOD WILL WORK}

Frozen ground works in loose and water bearing soil will take the following actions to protect the excavation:

- Artificial ground freezing applications rely on the increased strength and stiffness of soils, when they are frozen, to provide temporary support to excavations. Soil grains, structural unfrozen water, ice and water may be contained in the complex frozen soil. Applied stresses are shared between the ice and soil skeleton. 
- As compressive strength of frozen soil is much higher than that of unfrozen loose soil, freezing will prevent the excavation from collapse by strengthening the rock column. The following figure shows how strength of sand, silt and clay increase with decreasing temperature.

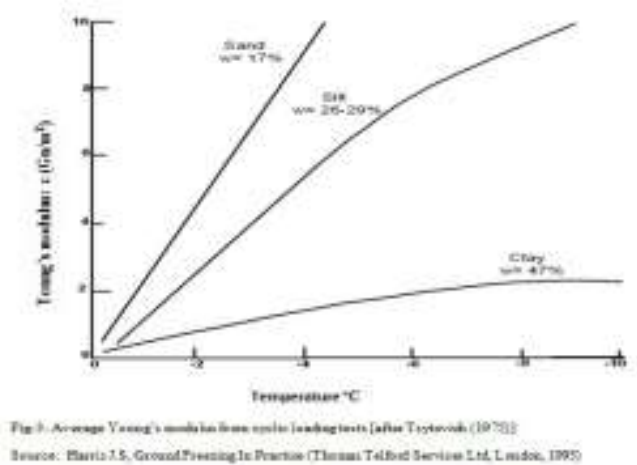

- Freezing around the selected excavation area will create a frozen earth barrier to act as bar to water to inrush

- It is possible to control the strength of freezing wall as required water level.

It was mentioned before that this method is environment friendly and has nearly no effect on ground

Hence, AGF method is a reliable solution to the soil-structure interaction problem we are concerned about. So, the method under consideration would be highly optimistic and efficient to control the high water inflow of the Dupitila aquifer. Freezing will also increase the strength of the loose formation from collapsing after excavation.

\section{Heading Caisson Sinking ANd Dewatering Method For Shaft Sinking}

Two very common methods for shaft sinking are caisson sinking and ground water lowering or dewatering. They are introduced in brief and the reason they should not be appropriate in case of Khalashpir basin is mentioned below:

1.1 Caisson Sinking: Caisson sinking requires the construction on the surface of the complete structure, ready for sinking into the ground with the help of kentledge. The method relies on relatively uniform, weak soil through which the caisson can penetrate by cutting and displacement of the soil until the target depth reached. A change of soil density can lead to frustration, while the random presence of hard obstruction (boulders) can deflect the caisson from the vertical, remobilizing a stood caisson is time consuming and costly. Dupitila aquifer containing basal gravels of braided river system by which the formation has been deposited may be a major concern for leading the caisson vertical.

1.2 Ground Water Lowering or Dewatering: In a large open site where it is not necessary to limit the extent of the excavation during the construction stage, a low cost option is 'dewatering', i.e. depression of the water table, by pumping, to a level below that of the intended excavation. This may be achieved by a series of well points inserted, usually be jetting techniques at relatively close spacing (approximately $1 \mathrm{~m}$ ) around the perimeter of the area.

Care must be taken to avoid the withdrawal of 'fines' - e.g. silt/fine sand particles - with the water yield, since this could lead to subsidence and/or loss of support to neighboring property, depending on the size of the cone depression.

Implementation of this process against Dupitila aquifer which is huge in extent will need a huge area to be depleted which will lead subsequently water scarcity to the people of surrounding area. Again, pumping out of enormous amount of water may lead to subsidence of this loose column of rock and hence, damage to the land due to pumping is a burning issue.[ [1] Harris J.S, Ground Freezing In Practice (Thomas Telford Services Ltd, London, 1995).]

\section{CONCLUSIONS}

Dupitila aquifer containing basal gravels may be a major concern for leading the caisson vertical. So considering the geoenvironment, caisson cannot be the right chose for Khalashpir coal field.

Implementation of dewatering against Dupitila aquifer needs a huge area to be depleted, leading subsequently water scarcity to the people of surrounding area. Pumping out of enormous amount of water may lead to subsidence of this loose column of rock and hence, damage to the land is a burning issue. SO once again this method also cannot be the right choice. 
Selection Of Shaft Sinking Method For Underground Mining In Khalashpir Coal Field, Khalashpir,

Artificial ground freezing will prevent the excavation from collapse by creating frozen earth barrier. The ultimate result of which is increase in strength of loose soil. It is also capable of controlling moving ground water. This method is environment friendly, has nearly no effect on ground water level and safe. So freezing method should be adopted for the shaft sinking purpose.

Artificial ground freezing is a well proven technique which has been effectively used worldwide for shaft sinking to overcome the same condition as in Khalashpir.

Pumping test data of GTB-1 shows that Dupitila Formation is highly threatening in terms of water saturation and water flow to cause vigorous water inrush. This loose and low strength rock unit is also alarming for shaft construction rendering collapse of the structure. As freezing is time consuming and costly, the Dupitila unit should be frozen wholly and the rest two units ( Jamalganj Formation and Gondwana Group) which have very low water flow and compacted enough, they would be manageable by grouting.

Barapukuria coal field and Madhyapara hard rock mine of Bangladesh where prevailing the same problem of Dupitila aquifer, the successful practice was artificial ground freezing method for mine shaft sinking.

Finally our research out comes reveal that, the concerned authority have to go for freezing methods for vertical shaft sinking by conventional freezing method which will be environmental friendly and cost effective method for Khalashpir coal field

\section{REFERENCES}

Journal Papers:

[1] Harris J.S, Ground Freezing In Practice (Thomas Telford Services Ltd, London, 1995)

[2] Osborne J, Shaft Excavation In Frozen Ground At Point 5.

Theses:

[3] Mondal Debasis, MSc thesis (2004) Selection of Mining Method in The Khalashpir Coal Field, Rangpur, Bangladesh.

\section{Unpublished Papers:}

[4] China Jinan Mining Development Corporation (2006) Techno-economic Feasibility Study of Khalashpir Coal Mine Project, Dhaka, Bangladesh (unpublished).

[5] Dr. Yong Om Kil, Khalashpir Coal Mine Project, Pirganj, Rangpur (2005) Pumping Test Report of Exploration Boreholes on Khalashpir Coal Field (unpublished).

[6] Korea South-South Cooperation Corporation (1997) Construction of Skip Shaft-1 (Freezing Sinking Section) Technical Design (unpublished).

[7] Korea South-South Cooperation Corporation (NAMNAM) (2005) Recommendation on Selection of Conceptional Shaft Location on Khalashpir Coal Field (unpublished). 